\title{
A study of sequential blanking and overprinting combined ${ }^{1}$
}

\author{
M. E. TRESSELT, M. S. MAYZNER, ${ }^{2}$ K. M. SCHOENBERG, AND J. WAXMAN \\ NEW YORK UNIVERSITY
}

By presenting alphabetic and other types of input characters, in either adjacent spatial locations or in the same spatial location, on the face of a cathode-ray tube (CRT) interfaced to a digital computer and by varying in systematic ways the interstimulus intervals (ISIs) and display orders of the several sequentially presented inputs, there has evolved what we call a "blanking-overprinting" paradigm. The use of such a paradigm has disclosed that the visual system can operate in a very sensitive and highly selective manner, "clearing" the first of two overprinted inputs that are separated in time bv as little as 50 usec, while selectively inhibiting the second of these two overprinted inputs, if appropriate blanking inputs are present.

In a number of recent studies concerned with visual information processing in man, trains of stimuli have been displayed io the visual system at varying input rates and in varying spatial configurations. In one set of studies (Buchsbaum \& Mayzner, 1969; Mayzner \& Tresselt, 1969, 1970; Mayzner, Tresselt, \& Cohen, 1966; Mayzner, Tresselt, \& Helfer, 1967a,b) the stimuli, which consisted of line segments, various geometric shapes, and alphanumeric symbols, always occurred in different spatial locations on the face of a cathode-ray tude (CRT) display, while in a second set of studies (Greenberg, Helfer, \& Mayzner, 1968; Katz, Schoenberg, \& Mayzner, 1970; Mayzner, Tresseit, Checkes, \& Hoenig, 1970; Mayzner, Tresselt, Tabenkin, Didner, \& Helfer, 1969) the stimuli, which consisted of letters, digits, and words, were always displayed in the same spatial location on the CRT face, i.e., one stimulus or input was displayed directly on top of another.

The first set of studies disclosed an apparently new perceptual phenomenon we have called "sequential blanking," in which, at appropriate input rates and display orders, up to half of the stimuli may not be perceived. Thus, the word CHAIR may be seen as C A R if $H$ is displayed first, I second, $C$ third, $A$ fourth, and $R$ fifth, i.e., using the display order 31425 or the sequence -..- may be seen as ... if the input rate is, for example, $20 \mathrm{msec}$ on per input and $20 \mathrm{msec}$ off between inputs. This sequential blanking effect is a typical U-shaped function (Mayzner, Tresselt, \& Helfer, 1967b) in that if on and off times are reduced to, for example, $5 \mathrm{msec}$, all five inputs are typically perceived as occurring simultaneously, while if on and off times are increased to, for example, $100 \mathrm{msec}$, all five inputs are typically perceived as occurring sequentially.

The second set of studies mentioned above, in which several inputs are displayed one on top of another and which we have called the "overprinting" phenomenon, reveals a typical monotonic function in which, as the off time between inputs or interstimulus interval (ISI) is decreased for a given, brief on time (e.g., $20 \mathrm{msec}$ ), a marked degradation of inputs results. Complicated interactions in this degradation process also result as the number of overprinted inputs increases and ISI values decrease.

In the present study, we shall be concerned with combining the sequential blanking paradigm and the overprinting paradigm just described into a single composite blanking-overprinting paradigm. For example, suppose we display the sequence BBBBB sequentially, with the display order 314425 at $20 \mathrm{msec}$ on $/ 20 \mathrm{msec}$ off per letter. We know that with this display order and input rate, S will typically report B B B. We also know that if we display $N$ for $20 \mathrm{msec}$, following it 50 microsec later with $B$, also for $20 \mathrm{msec}$, in the exact same display location, $\mathrm{S}$ will typically report a jumble of points or a "noise-like" input with no letter, either $B$ or $N$, being perceived. Now, suppose we display the following sequence sequentially $B(N B) B(N B) B$, in which the two NBs in parentheses are overprinted (i.e., $\mathbf{N}$ first, then $B)$ with the display times just indicated, followed by three single Bs, with the seven separate inputs displayed with the order $5(12) 6(34) 7$, with all on and off times equal to $20 \mathrm{msec}$ except for the off times between the two overprinted inputs, which is 50 microsec. The question posed is: "Will the three blanking inputs, i.e., B B B selectively blank or erase the two Bs in Display Locations 2 and 4, thus "clearing" these display slots of Bs and so permitting $S$ to detect the presence of the Ns?" The present study, consisting of two experiments, seeks an answer to this question.

\section{EXPERIMENT 1}

Method

Subjects. Fourteen graduate students selected randomly at the University Heights campus of New York University served as Ss.

Apparatus. The stimuli were presented on two Fairchild CRT display consoles simultaneously, both slaved to a 340 Master Display driven by a PDP-7 digital computer. A complete description of this hardware system and its associated computer programs (software) may be found in previous papers (Mayzner, 1968: Mayzner et al, 1967a).

Materials and procedure. Since we wished to obtain a set of overprinted letter pairs that would yield a marked degradation of both inputs, some 60 letter pairs, such as $B$ and $N, G$ and $P, B$ and $X$, etc., were displayed, using the overprinting paradigm alone, to a small sample of Ss $(\mathrm{N}=4)$ four times each in a random order for a total of 240 trials. The on + off + on time combination for each letter pair was $20 \mathrm{msec}$ on +50 microsec off $+20 \mathrm{msec}$ on. As might be expected with such on-off times, percent correct letter detections was low and the 10 pairs of the 60 pairs showing the lowest detection values were selected for the combined blanking-overprinting paradigm. For these 10 lowest pairs, the average percent correct detections of letters was only $9.5 \%$ and the 10 pairs were as follows: $B$ and $N, G$ and $P$, $B$ and $X, G$ and $N, I$ and $V, N$ and $P, N$ and $S, Z$ and $N, P$ and $O$, and $P$ and $S$.

For each of these 10 pairs two basic blanking-overprinting patterns were generated. For example, the letter pair B and $\mathrm{N}$ yielded the blanking-overprinting pattern previously described in the introduction, i.e., $B(N B) B(N B) B$ with the display order $5(12) 6(34) 7$, and the inverse pattern $N(B N) N(B N) N$ also was generated with the same display order and input rate. It should be noted that with the display sequences selected, the five identical inputs, e.g., five Bs or five Ns, were deliberately selected to be identical since numerous previous studies (Buchsbaum \& Mayzner, 1969; Mayzner \& Tresselt, 1969, 1970; Mayzner et al, 1967a,b) had very clearly demonstrated that sequential blanking effects are maximized when all inputs involved in the blanking sequence are identical in geometric configuration. Since we knew (Greenberg, Helfer, \& Mayzner, 1968) that as ISI values increase with overprinted letter pairs, percent correct detections increase, we also wished to study the effect of this ISI parameter on 
the blanking-overprinting patterns. Thus, five ISI values were selected for the separation time of the two overprinted inputs, namely, 50 microsec and $1,10,50$, and $100 \mathrm{msec}$, while on and off times for the remaining five identical letters in the arrays were always held constant at $20 \mathrm{msec}$ on $/ 20 \mathrm{msec}$ off. It should be noted that when the ISI value between the two overprinted inputs is only 50 microsec, the off time [with the sequence $\mathrm{B}(\mathrm{NB}) \mathrm{B}(\mathrm{NB}) \mathrm{B}]$ between the first $\mathrm{B}$ (i.e., Input 2) displayed and the second $B$ (i.e., Input 4) displayed is occupied with displaying the second $\mathrm{N}$ (i.e., Input 3 ) for $20 \mathrm{msec}$ (actually $20 \mathrm{msec}$ minus 50 microsec). However, when the ISI values between the two overprinted inputs increase and we still wish to maintain the $20 \mathrm{msec}$ on $/ 20 \mathrm{msec}$ off times for the five identical inputs, the aforementioned condition no longer obtains. Thus, depending on the ISI values between the overprinted inputs, adjustments are made in the display order and timing such that the last five inputs displayed (i.e., $20 \mathrm{msec}$ on $/ 20 \mathrm{msec}$ off) occur with the display order $3(x 1) 4(\times 2) 5$, with the $x s$ in parentheses indicating that the first of the two inputs in those display locations occurs earlier in time by the appropriate amount, i.e., 1, 10,50, and $100 \mathrm{msec}$, than the second input in those display locations.

With 10 different letter pairs, each generating two patterns [i.e., $\mathrm{B}(\mathrm{NB}) \mathrm{B}(\mathrm{NB}) \mathrm{B}$ and $\mathrm{N}(\mathrm{BN}) \mathrm{N}(\mathrm{BN}) \mathrm{N}]$ or a total of 20 different patterns, and with each pattern examined at one of five different ISI values, each of the $10 \mathrm{Ss}$ of the study (not including the $4 \mathrm{Ss}$ used to obtain the overprinted pairs) received a total of 100 test trials, plus 40 additional control trials randomly mixed with the 100 test trials. These 40 control trials were composed of two sets, Control 1 (20 trials) and Control 2(20 trials and were either of the form A(NB)A(NB)A or X(NB)Y(NB)Z, in which the blanking letters were all identical or all different but also different from the overprinted letters. These control trials were included to ensure that identity or high similarity of input geometry between the blanked and blanking inputs is required, if sequential blanking effects are to operate maximally. Only one ISI value was examined with the control trials, namely, 50 microsec.

On each trial $S$ was instructed, when $\mathrm{E}$ said "ready," to fixate on a small black fixation point, $1 / 4$ in. in diam, pasted to the CRT display surface, $1 / 4$ in. above the middle character of each five-character array. $S$ was further instructed that within about 1/2 sec of being told "ready," he would see a display of letters and that he was to write down on a prepared response form the content of the display area just to the right and left of the letter directly under the black fixation point. This region might appear empty or blurred or might disclose one or two letters that might be the same or different from the other three letters of the array, which would always be quite clear but were to be ignored. Previous pilot work had shown that Ss found this task quite simple to understand and the results of the study amply confirmed this expectation. Display luminance was $1 \mathrm{~mL}$, individual letter size was $1 / 2$ in. high and $3 / 8 \mathrm{in}$. wide, and $S$ was positioned $3 \mathrm{ft}$ in front of the CRT display with his head firmly positioned in a head and chin rest. A dim background light sufficient for $S$ to record his responses was provided by a 25-W tensor lamp located $10 \mathrm{ft}$ from the scopes and directed towards the ceiling and away from the scopes.

\section{Results}

The results of Experiment 1 are quite clear and are shown in Table 1. In Table 1 the percent correct letter detections, i.e., the percent detections of the first of the two overprinted inputs, as well as the percent of empty or blurred responses, and the percent of incorrect letter responses are shown for the five ISI values of the study. It is interesting to note that no $S$ ever saw the second letter of the two overprinted letters with the blanking-overprinting paradigm. Also shown in Table 1 is the percent correct detections when no blanking inputs were present, i.e., the pure overprinting condition. An application of the Friedman two-way analysis of variance by ranks test (Siegel, 1956, pp. 166-172) applied to the mean percent correct detections for the five ISI values shown in Table 1 yield a $\chi_{\mathrm{r}}^{2}=35.20, \mathrm{p}<.001$. The findings for Controls 1 and 2 are almost identical with the pure overprinting condition for mean percent correct detections (i.e., $12.5 \%$ and $10.0 \%$ vs $9.5 \%$ ), clearly confirming our earlier findings concerning the effects of input geometry on sequential blanking (Mayzner et al, 1967b).

Two principal findings emerge from Table 1. First, an almost fourfold increase in percent correct detections, i.e., an increase from $9.5 \%$ with pure overprinting to $37 \%$ with a blanking pattern added, is possible with only a 50-microsec ISI value. This finding suggests a far higher degree of temporal resolving power than is typically attributed to the visual system. Second, as ISI values increase from 50 microsec to $100 \mathrm{msec}$, percent correct detections for the first of the two overprinted inputs systematically increases from $37 \%$ to $93 \%$. This finding would appear to demonstrate that sequential blanking can operate
Table 1

Mean Percent Correct Detections, Empty or Blurred Responses, and Incorrect Detections for the Five ISI Values of Experiment I*

\begin{tabular}{cccc}
$\begin{array}{c}\text { ISI } \\
\text { Values }\end{array}$ & $\begin{array}{c}\text { Mean } \\
\text { Percent } \\
\text { Correct } \\
\text { Detections }\end{array}$ & $\begin{array}{c}\text { Mean } \\
\text { Percent } \\
\text { Empty/Blurred } \\
\text { Responses }\end{array}$ & $\begin{array}{c}\text { Mean } \\
\text { Percent } \\
\text { Incorrect } \\
\text { Detections }\end{array}$ \\
\hline 50 usec $^{* *}$ & 37.0 & 41.0 & 22.0 \\
$1 \mathrm{msec}^{* * *} 43.0$ & 31.0 & 26.0 \\
$10 \mathrm{msec}$ & 56.0 & 25.0 & 19.0 \\
$50 \mathrm{msec}$ & 92.0 & 4.0 & 4.0 \\
$100 \mathrm{msec}$ & 93.0 & 3.0 & 4.0 \\
Control 1 & 12.5 & 25.0 & 62.5 \\
Control 2 & 10.0 & 26.5 & 63.5 \\
Pure & 9.5 & & 90.5 \\
Overprinting & & & \\
\hline
\end{tabular}

* The percent correct and incorrect detections refer to the first input in the blanking-overprinting paradigm. ** usec $=$ microsecond: $\quad * * *$ msec $=$ millisecond

selectively at least some of the time, to blank or erase one input while permitting a second input, in the same spatial location and which may be as close as 50 microsec in time to the first input, to be "cleared" through the system. If selective inhibition of form, pattern, or contour information is, in fact, possible, it would seem desirable to know if this was true only when both overprinted inputs were letters or if this was also possible when the blanking inputs were not letters. Therefore, a second experiment was performed using a somewhat different methodology to determine if the selective inhibition effect could be replicated, especially with blanking inputs that were not letters.

\section{EXPERIMENT 2}

Method

Subjects. Ten graduate students selected randomly at the University Heights campus of New York University served as Ss. None of these 10 Ss had served in Experiment 1.

Apparatus. The apparatus for Experiment 2 was identical to that used in Experiment 1.

Materials and procedure. Since in Experiment 1 we had employed only 10 different letter pairs and, further, since these pairs involved only 10 different letters of the alphabet (i.e., $B, G, I, N, O$, $P, S, V, X$, and $Z$ ) with many letters $(N$, for example) appearing in several different pairings, we believed it important to replicate the basic paradigm of Experiment 1 but to employ a much wider range of input content. Also, most importantly, we wished to employ blanking inputs that were not letters. This was achieved by employing for the five identical inputs the "number" character, i.e., \#\#, previous work having shown (Mayzner et al, 1967b) that the display order 31425 with five \#s yield a visual experience of \#\#, with the usual two 
characters being displayed first and second in Display Locations 2 and 4 not being perceived. It should be noted that the \# character, when displayed on the CRT, appears with the vertical lines perfectly vertical, rather than at a slight oblique as with printed type. A complete description of all letter characters and the \# character may be found in Mayzner et al, 1967a).

All letters of the alphabet were employed, except $Q$, yielding a pool of 25 different letters or input characters for the blanking-overprinting paradigm. Two control sets of input trials were employed as follows: Each $S$ received 25 displays such as A A, B B, C C, etc. and 25 displays

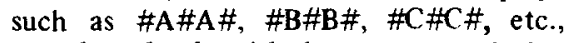
mixed randomly with the pure overprinting and blanking-overprinting displays to be described shortly. For all displays $\mathbf{S}$ was instructed as in Experiment 1 and was told to write down after each display the letters he had perceived. In the control set $\mathbf{A} A$, etc. the left $A$ was on for $20 \mathrm{msec}$. followed by a 20 -msec pause, at which time the right $A$ was displayed for $20 \mathrm{msec}$. In the control set \#A\#A\#, etc., the display order was always 31425 , i.e., the left $A$ displayed first, the right $A$ second, the extreme left \# third, etc., with $20 \mathrm{msec}$ on $/ 20 \mathrm{msec}$ off $p \mathrm{r}$ in put character. Since both control sets yielded almost totally errorless performance with respect to detecting what letter was present, i.e., $99 \%$ and $98 \%$ correct detections, respectively, and since these results are in complete agreement with our previous findings (Mayzner et al, 1967a,b), which demonstrated (1) that $20 \mathrm{msec}$ is more than ample time to correctly detect a character and (2) that sequential blanking with the display order 31425 does not occur for the inputs displayed first and second (if their input geometry is sufficiently different from the input geometry of the inputs displayed third, fourth, and fifth), nothing further will be said about these results.

For the blanking-overprinting trials, five sets of 25 trials each were constructed, with each set employing each of the 25 different letters of the alphabet just once. In these 125 trials, as in Experiment 1, the overprinting occurred in Display Locations 2 and 4 , with the alphabetic characters occurring with or before the \# characters. We have said "with," since in one of the five sets the alphabetic character was displayed simultaneously with the \# character, so a base level of performance would be available for comparison with the ISI values of the overprinted characters in the remaining four sets. The remaining four sets had ISI values between the two overprinted inputs of $50 \mathrm{microsec}$, and 1 , 20 , and 40 msec.

Table 2

Mean Percent Correct Detections for Overprinting and Blanking-Overprinting Patterns

\begin{tabular}{llccccc} 
& & \multicolumn{5}{c}{ ISI Values } \\
\cline { 3 - 6 } & & Simultaneous & 50 Usec & $1 \mathrm{Msec}$ & $20 \mathrm{M} \mathrm{sec}$ & $40 \mathrm{M} \mathrm{sec}$ \\
\hline Percent & Pure Overprinting & $51 \%$ & $55 \%$ & $58 \%$ & $78 \%$ & $92 \%$ \\
Correct & Blanking-Overprinting & $27 \%$ & $72 \%$ & $80 \%$ & $92 \%$ & $95 \%$ \\
\hline
\end{tabular}

In addition, 125 overprinting control trials were constructed which were identical to the 125 blanking-overprinting trials, except that the final three input characters, i.e., \# \# \#ere not displayed, so that for each of the five sets of 25 trials (i.e., simultaneous, 50-microsec ISI, 1-msec ISI, 20 -msec ISI, and $40-\mathrm{msec}$ ISI) a direct comparison could be made on each of the 10 Ss employed between their percent correct letter detections with pure overprinting vs blanking-overprinting. Thus, each $S$ received a grand total of 300 trials (two control sets of 25 trials each + 125 pure overprinting trials +125 blanking-overprinting trials) mixed randomly and was required to indicate for each trial what identical pair of letters he perceived and to write them down on prepared response forms. In all other respects, such as display luminance, size of characters, distance of $S$ from CRT, etc. Experiments 1 and 2 were identical.

\section{Results}

Table 2 presents the principal findings of Experiment 2, and it may be seen that the results very clearly replicate the findings of Experiment 1. For the four different ISI values examined, i.e., 50 microsec, and 1 , 20 , and $40 \mathrm{msec}$, an application of the sign test (Siegel, 1956, pp. 68-75) yield p values $<.001, .001, .001$, and .03 , respectively; with the simultaneous condition, $\mathrm{p}<.002$ is obtained but, interestingly, with this condition significantly fewer errors are made with the pure overprinting pattern, the reverse of what was found for the four different ISI value conditions. We believe this seemingly anomolous result occurs because, with the simultaneity of the two inputs in the blanked locations and with blanking inputs on either side, it becomes far more difficult for $S$ to decipher the letter character and the \# character or both are blanked together as a result of the typical sequential blanking effect for these display locations, than with the pure overprinting case in which no distracting blanking \# characters are present in the visual field to further complicate matters. Further, an application of the Friedman two-way analysis of variance by ranks test (Siegel, 1956, pp. 156-172) to the five conditions under the pure overprinting and blanking-overprinting paradigms yield $\chi_{r}^{2}=32.62$ and 35.30 and associated $p$ values $<.001$, respectively.

\section{DISCUSSION}

The results of Experiments 1 and 2 taken together provide strong evidence, we believe, for certain visual information processing mechanisms discussed at some length in two previous theoretical papers (Mayzner \& Tresselt, 1970; Mayzner et al, $1967 \mathrm{~b}$ ). Very briefly, we assumed that if two inputs directly overprinted one another their excitatory fields would directly interact, resulting in a marked degradation of the perceptability or detectability of both inputs as the ISI time between them decreased. Such input degradation was observed in a number of studies (Greenberg et al, 1968; Katz et al, 1970; Mayzner et al, 1970; Mayzner et al, 1969) as a function of decreasing ISI times and input list length.

In other studies on sequential blanking effects (Buchsbaum \& Mayzner, 1969; Mayzner \& Tresselt, 1969; Mayzner et al, $1967 \mathrm{a}, \mathrm{b})$, we assumed that with a string of adjacently displayed inputs, if appropriate input display orders and input display rates sbtained as well as certain relationships between the input geometry or content of these inputs, then excitatory-inhibitory field interactions might occur, also resulting in a falure to detect certain inputs in the input string.

In the present study we have combined both the overprinting and blanking paradigms into a single composite blanking-overprinting paradigm. These results seem to suggest that the interacting excitatory fields of the two overprinted inputs, particularly at low ISI values (e.g., 50 microsec, and $1,10 \mathrm{msec}$, etc.), most probably are coded together in the "subjective visual experience" (SVE) component of our model (Mayzner \& Tresselt, 1970; Mayzner et al, 1967b), since they are experienced together much of the time as a composite jumble of points or a visual noise field (if no blanking inputs are present). They most probably are also coded separately at least some of the time at a point prior to SVE, since the inhibitory fields of the blanking inputs operate selectively some of the time to blank only one of the two inputs in the blanked locations. Evidence for this selective blanking or inhibition may be found in both Tables 1 and 2 and, while the absolute percent of correct letter detections varies between Tables 1 and 2 , percent correct letter detections for 
blanking-overprinting is superior to pure overprinting in both Tables 1 and 2 .

Our results also tend to support the "disinhibition" findings of Dember and Purcell (1967), Robinson (1966, 1968), and Schiller and Greenfield (1969), who were concerned with a paradigm in which, in general, three visual inputs (i.e., a target input, a masking input 1 and a masking input 2) were presented sequentially. In these studies, it was found that detection of the target input was significantly greater when Masks 1 and 2 followed the target than when the target input and Mask 1 were presented alone. Our blanking-overprinting paradigm is somewhat similar to these other studies; however, it also differs significantly from them in that our ISI times for the two overprinted inputs fall as low as 50 microsec and, more importantly, our results indicate that sequential blanking can operate in a highly selective way, "clearing" only one of the two overprinted inputs for passage through the system or detection by the system, whereas the "disinhibition" effect, as studied previously, has not been shown to operate selectively.

Uttal, ${ }^{3}$ in a very recent study, faijed to find a disinhibition effect employing a target letter (made up of dots on a CRT) followed by two overprinted noise fields of 100 dots each, which appears to contradict our findings and the other disinhibition studies cited above. However, it would be our position that in the Uttal study the second noise field did not inhibit the first noise field and thus "clear" the target letter, because the spatio-temporal relationships between the two noise fields and the target letter were not appropriately manipulated to allow for disinhibition to occur. In effect, Uttal is, in our terms, overprinting three inputs or three excitatory fields which directly interact with one another, producing the type of overall input degradation we have found with such input strings (e.g., Mayzner et al, 1970).

Our major finding, that the blanking-overprinting paradigm can operate selectively, "clearing" a target input through the visual system while inhibiting a second overprinted input, provides a novel methodology for studying problems of pattern or form perception. For example, by systematically varying the input geometry of the two overprinted inputs and their relationship to the input geometry of the blanking inputs, as well as varying the ISI and input on times involved, we should be able to more precisely specify the coding routines used by the visual system in pattern perception.

Finally, we would speculate that the type of disinhibition shown by the human visual system in the present study may well be a direct analogue of the classic disinhibition phenomena reported by Hartline and Ratliff (1954, 1957) and discussed at length by Ratliff (1965) with "Limulus." Its highly selective operation, found in the human visual system, in inhibiting only the second of the two overprinted inputs, which is identical in geometrical configuration to the three blanking inputs, is a direct function, as we have argued previously (Mayzner \& Tresselt, 1970; Mayzner et al, 1967b), of our assumption that the five geometrically identical inputs are processed in sufficiently close spatial proximity in a columnar matrix of the type discussed by Hubel and Wiesel (1968), where inhibitory fields may interact while the first of the two overprinted inputs is "routed" to a different spatial.location in this columnar matrix because of its different geometrical properties, thus not allowing for inhibitory freld interactions to occur. Since our present visual information processing model (Mayzner \& Tresselt, 1970) makes extensive use of the complex excitatory and inhibitory fjeld interactions that occur in the visual system, further confirmation and elaboration of the disinhibition phenomena and its highly sensitive and selective operation in man's visual system is encouraging.

\section{REFERENCES}

BUCHSBAUM, W. H., \& MAYZNER, M. S. The effects of line length on sequential blanking. Psychonomic Science, 1969, 15, 111-112.

DEMBER, W. N., \& PURCELL, D. G. Recovery of masked visual targets by inhibition of the masking stimulus. Science, 1967, 157, 1335-1336.

GREENBERG， M., HELFER, M. S., \& MAYZNER, M. S. Information processing of letter and word paiss as a function of on and off times. Perception \& Psychophysics, 1968 $4,357-360$.

HARTLINE, H. K., \& RATLIFF, F. Spatial summation of inhibitory influences in the eye of limulis. Science, 1954, 120, 781 .

HARTLINE, H. K., \& RATLIFF, F. Inhibitory interaction of receptor units in the eye of Limulus. Journal of General Physiology, 1957, 40, 357-376.

HUBEL, D. H., \& WIESEL, T. N. Receptive fields and functional architecture of monkey striate cortex. Journal of Physiology, 1968, 195, 215-243.

KATZ, M., SCHOENBERG, K. M., \& MAYZNER, M. S. Visual information processing of sequentially presented inputs: II. Effects of list length and interstimulus interval values on subspan storage and retrieval mechanisms. Perception \& Psychophysics, $1970,7,149-152$.

MAYZNER, M. S. The research potential of a computer-based cathode-ray tube display system. Behavior Research Methods \& Instrumentation, 1968, 1. 41-43.

MAYZNER, M. S., \& TRESSELT, M. E. Sequential blanking: A function of geometric analyzers in the human visual system. Psychonomic Science, 1969, 17, 77-78.

MAYZNER, M. S., \& TRESSELT, M. E. Visual information processing with sequential inputs: A general model for sequential blanking, displacement, and overprinting phenomena. Annals of the New York Academy of Sciences, in press.

MAYZNER, M. S., TRESSELT, M. E., \& COHEN, A. Preliminary findings on some effects of very fast sequential input rates on perception. Psychonomic Science, 1966, 6, 513-514.

MAYZNER, M. S., TRESSELT, M. E., \& HELFER, M. S. A research strategy for studying certain effects of very fast sequential input rates on the visual system. Psychonomic Monograph Supplements, 1967a, 2(5, Whole No. 21 , 73-81.

MAYZNER, M. S., TRESSELT, M. E., \& HELFER, M. S. A provisional model of visual information processing with sequential inputs Psychonomic Monograph Supplements, 1967b, 2(7, Whole No. 23), 91-108.

MAYZNER, M. S., TRESSELT, M. E. CHECKES, J., \& HOENIG, H. A. Visual information processing of sequentially presented inputs: III. Further effects of list length and interstimulus interval values on subspan storage and retrieval mechanisms. Perception \& Psychophysics, 1970, 7, 294-296.

MAYZNER, M. S., TRESSELT, M. E. TABENKIN, N., DIDNER, R.. \& HELFER, M. $S$. Visual information processing of sequentially presented inputs: I. Effects of input timing on subspan storage and retrieval mechanisms. Perception \& Psychophysics, 1969, 5, 297-302.

RATLIFF, F. Mach bands: Quantitative studies on neural networks in the retina. San Francisco: Holden Day, 1965.

ROBINSON, D. N. Disinhibition of visually masked stimuli. Science, 1966, 154, 157-158. ROBINSON, D, N. Visual disinhibition with binocular and interocular presentations. Journal of the Optical Society of America, $1968,58,254-257$.

SCHILLER, P. H., \& GREENFIELD, A. Visual masking and the recovery phenomena. Perception \& Psychophysics, 1969, 6, 182-184.

SIEGEL, S. Nonparametric statistics for the behavioral sciences. New York: McGraw-Hill, 1956.

\section{NOTES}

1. This research was supported by Grant No. GB-8037 from the National Science Foundation to the second author.

2. Address: 15 Sydney Avenue, Deal, New Jersey 07723.

3. Uttal, W. R. On the physiological basis of masking with dotted visual noise. Unpublished manuscript, 1969 .

(Accepted for publication January 2, 1970.) 